\title{
Thioacetamide promotes osteoclast transformation of bone marrow macrophages by influencing PI3K/AKT pathways
}

\author{
XiaoLi Jin ${ }^{1 \dagger}$, Yang Li ${ }^{2 \dagger}$, Yayang Yang ${ }^{3}$, Hao Shen ${ }^{1}$, Jin Chen ${ }^{1}$, Bin $\mathrm{Xu}^{4^{*}}$ and Jian $\mathrm{Xu}^{1^{*}}$ (0)
}

\begin{abstract}
Background: Osteoclast cell increase is a major risk factor for osteoporosis and degenerative bone and joint diseases. At present, RANKL and M-CSF are commonly used to induce osteoclastogenesis. Thioacetamide (TAA) can lead to many types of liver and kidney damage, but less attention has been paid to the association of TAA with bone damage. In this work, we investigated the effects of TAA on the osteoclastogenesis and differentiation of bone marrow macrophages (BMMs).

Methods: BMMs of SD rat suckling mice were taken for primary culture. CCK-8 was used to detect the toxic effects of TAA on BMMs, and flow cytometry was used to detect the effects of TAA on the cell cycle, cell viability, apoptosis and intracytoplasmic $\mathrm{Ca}^{2+}$ concentration of BMMs. TRAP staining was used to detect the effect of RANKL and M-CSF and TAA on osteoclast differentiation of BMMs. Western Blot was used to detect the expression level of PI3K/AKT pathway and osteoclast-specific proteins (TRAP and cathepsin K).
\end{abstract}

Results: The results suggested that TAA inhibited the proliferation of BMMs, while enhancing osteoclastogenesis at $0.5 \mathrm{mg} / \mathrm{mL}$ and $1 \mathrm{mg} / \mathrm{mL}$ as assayed by TRAP staining. Exposed to TAA, BMMs could differentiate into osteoclast-like cells with overexpression of cathepsin $\mathrm{K}$ and TRAP proteins. Western blot results showed that TAA can activate the expression levels of P-PI3K, P-AKT, P-P38, and P-JNK, accompanied by apoptosis of BMMs and increase in intracellular $\mathrm{Ca}^{2+}$.

Conclusion: TAA may induce osteoclast formation in BMMs by activating the expression of PI3K/AKT pathway proteins, which is comparable to the classic osteoclast differentiation inducer RANKL and M-CSF. This suggests that we may find a cheap osteoclast inducer.

Keywords: Thioacetamide, Osteoclast, Macrophages, RANKL, Cell differentiation

*Correspondence: 3304089@zju.edu.cn; xujian832002@163.com

${ }^{\dagger}$ XiaoLi Jin and Yang Li have contributed equally to this work

${ }^{1}$ School of Medical Technology and Information Engineering, Zhejiang

Chinese Medical University, Hangzhou 310053, China

${ }^{4}$ Department of General Surgery, School of Medicine, Sir Run Run Shaw

Hospital, Zhejiang University, Hangzhou 310016, Zhejiang, People's Republic of China

Full list of author information is available at the end of the article

\section{Introduction}

TAA as a commercial chemical is widely used in electroplating additives, photographic drugs, pesticides and dyeing aids [1-4], and it is used to establish an animal model for liver cirrhosis due to its hepatotoxic effects [5]. TAA-induced cirrhosis has similar pathologic changes to human liver cirrhosis and can be used to reproduce the human disease [6,7]. Additionally, the effects of TAA are not limited to the liver, as profound structural and functional changes have been described in the kidney, spleen, lung, intestine, stomach, brain and bone marrow after 
TAA exposure [8-15]. However, less attention has been paid to the association of TAA with bone damage.

In a previous experiment, operation staff found an interesting phenomenon in the classic liver cirrhosis animal model administered with TAA. Approximately, 40 to $50 \%$ of the animals presented open fractures, arthroncus and arthrorrhagia. No reports have expressly described bone damage caused by TAA. Lassila and Virtanen [16, 17] found that osteoblastic activity and osteoid were distinctly decreased, and found robust osteoclastic resorption, when the alveolar bone was under occlusal stress and TAA traumatization. Nakano and colleagues [18] also demonstrated that the bone volume in TAA-exposed cirrhotic rats was significantly lower, with a combination of low bone formation rates and high resorption rates.

Bone homeostasis in vivo depends on the balance in function of osteoblasts and osteoclasts, which are responsible for bone formation and bone resorption, respectively [19-22]. These cell populations are tightly coordinated with each other under normal conditions. When the immune function is abnormal, this balance will be broken [23], leading to diseases that affect bone loss, such as rheumatoid arthritis [24, 25], osteoporosis [26] and periodontitis [27].

BMMs possess self-renewal capacity and play a crucial role in modulating normal bone homeostasis, with the potential to differentiate into osteoclasts in vitro [28]. In vitro, receptor activator of nuclear factor kappa $B$ ligand (RANKL) and macrophage colony-stimulating factor (M-CSF) are used to induce osteoclast differentiation [29-31]. Under the co-stimulation of RANKL and M-CSF, the PI3K/AKT pathway was activated, upregulating the nuclear transcription factors NFATc 1 and c-Fos. Then, the expression of the osteoclast-specific proteins TRAP and cathepsin $\mathrm{K}$ increase, promoting the differentiation of osteoclast precursor cells into mature osteoclasts [32, 33]. However, RANKL and M-CSF are expensive and the preparation process is complicated, which complicates the study of osteoclasts in vitro. On the contrary, the preparation method of TAA is simple and cheap. TAA may induce osteoclast formation or increase the activity of these cells to cause bone damage. We sought to know whether TAA could induce osteoclastic transformation of BMMs in vitro, so as to find a better osteoclast inducer. Therefore, we conducted experiments to verify the effects of TAA on inducing osteoclastogenesis.

\section{Methods}

\section{Cells and cell culture}

Sprague-Dawley (SD) rats were purchased from Shanghai SLAC Laboratory Animal Co, Ltd. The BMMs were isolated from 2-day-old SD rats. The cells were cultured in growth media containing Dulbecco's modified Eagle's medium/Nutrient Mixture F-12(Ham) (DMEM/F-12(1:1) basic(1X); Sigma) supplemented with $10 \%$ fetal bovine serum (FBS; Sigma). The cultures were maintained at $37{ }^{\circ} \mathrm{C}$ in a humidified $5 \% \mathrm{CO}_{2}$ incubator. When the cells reached $80-90 \%$ confluency, about 5-8 days, cultures were harvested with Trypsin-EDTA solution $(0.25 \%$ trypsin, 1 mM EDTA; Sigma). The media was changed every $2-3$ days.

\section{Preparation of TAA}

TAA (CAS No. $62-55-5,>98.0 \%$ purity; Sang on Biotech, Shanghai, China) was dissolved in culture media (10 mg/ $\mathrm{mL})$, filter sterilized $(0.22 \mathrm{um})$ then diluted to desired concentrations for use in specific assays as described below.

\section{Cell cytotoxicity assay (CCK-8)}

CCK-8 assay was performed to assess the cytotoxic effect of TAA on BMMs. BMMs $\left(2 \times 10^{3}\right.$ cells/well $)$ were seeded into 96-well plates (Corning, USA) in a volume of $100 \mu \mathrm{L}$ and cultured overnight. Then, the culture media was replaced by media containing different concentrations of TAA $(0,0.5,1,1.5$, and $2 \mathrm{mg} / \mathrm{mL})$, and each concentration was used in 5 parallel wells after adherence. The media was replaced with $100 \mu \mathrm{L}$ of fresh media and $10 \mu \mathrm{L}$ of CCK-8 solution (CCK-8; Beyotime Institute of Biotechnology, Shanghai, China) after culture for 12, 24, $36,48,60,72,80$ and $96 \mathrm{~h}$, the cells were then incubated for an additional $2 \mathrm{~h}$, and the absorbance was measured at $450 \mathrm{~nm}$ with a microplate reader (Model 680; Bio-Rad Laboratories, Hercules, CA, USA). The cell viability and IC50 values were then calculated. The survival rate of BMMs $(\%)=$ experimental group A value/control group A value $\times 100 \%$. At least 3 independent experiments were performed.

\section{CFSE (5, 6-carboxyfluorescein diacetate succinimidyl oxy ester) assay}

BMMs were cultured in different concentrations of TAA solutions $(0,0.5$ and $1 \mathrm{mg} / \mathrm{mL})$ for $24 \mathrm{~h}$. Then, BMMs $\left(1 \times 10^{6}\right.$ cells $\left./ \mathrm{mL}\right)$ were labeled for $15-20 \mathrm{~min}$ at $37{ }^{\circ} \mathrm{C}$ with $3 \mu \mathrm{M}$ carboxyfluorescein diacetate succinimidyl ester (CFSE; Cell Trace CFSE Cell Proliferation Kit, Invitrogen) in PBS supplemented with $0.1 \%$ BSA. CFSE-labeled cells were washed three times with PBS for $5 \mathrm{~min}$ at $400 \mathrm{~g}$ at room temperature and then cultured overnight. Then, the culture media was replaced by media containing different concentrations of TAA $(0,0.5$ and $1 \mathrm{mg} / \mathrm{mL})$. The cells were then incubated for $24 \mathrm{~h}$. Cell fluorescence was evaluated by flow cytometry (Novo Cytec, ACEA, California, USA; 10,000 cells were analyzed in each sample), and the data were analyzed 
using Flow Jo 7.6 software. The division index $(\%)=$ the percentage of cells with reduced CFSE fluorescence intensity/the percentage of cells with constant CFSE fluorescence intensity. At least 3 independent experiments were performed.

\section{Cell cycle analysis}

BMMs were exposed to TAA $(0,0.5$ and $1 \mathrm{mg} / \mathrm{mL})$ for $24 \mathrm{~h}$. The cells were subsequently collected, washed with PBS and fixed with $75 \%$ ethanol overnight. The cells $\left(1 \times 10^{6}\right.$ cells $\left./ \mathrm{mL}\right)$ were then centrifuged for $5 \mathrm{~min}$ at $400 \mathrm{~g}$, incubated with $10 \mathrm{mg} / \mathrm{mL}$ RNase and $1 \mathrm{mg} / \mathrm{mL}$ PI (Multi Sciences, CCS012) at $37^{\circ} \mathrm{C}$ for $30 \mathrm{~min}$ away from light. Finally, the cell cycle distribution was analyzed by flow cytometry (Novo Cytec, ACEA, California, USA; 10,000 cells were analyzed in each sample). The percentage of cells in the G0-phase, the G1-phase, the S-phase, the G2-phase and the M-phase was analyzed by Cell Quest software (Becton Dickinson, Franklin Lakes, NJ). At least 3 independent experiments were performed.

\section{Wright-Giemsa stain and tartrate-resistant acid phosphatase (TRAP) stain}

BMMs $\left(1 \times 10^{6}\right.$ cells/well $)$ were cultured with RANKL $(50 \mathrm{ng} / \mathrm{mL})$ and M-CSF $(30 \mathrm{ng} / \mathrm{mL})$ or varying concentrations of TAA $(0,0.5$, and $1 \mathrm{mg} / \mathrm{mL})$ in a 6 -well plate for 7 days. Cells were fixed and stained with the Wright-Giemsa stain (C190805) and TRAP/ALP stain kit (code No. 294-67001), according to the instructions of the manufacturer. Osteoclasts were defined as TRAPpositive cells being stained purple under a light microscope. The number of TRAP-positive cells was analyzed by ImageJ software. At least 3 independent experiments were performed.

\section{Immunofluorescence}

BMMs $\left(1 \times 10^{6}\right.$ cells/well $)$ were plated onto $35 \mathrm{~mm}$ glass-based dishes (801002; NEST Biotechnology, New Orleans, LA, USA) one day before stimulation with RANKL and M-CSF or TAA. Cells were then fixed in $4 \%$ polyformaldehyde for $30 \mathrm{~min}$ and permeabilized with $0.2 \%$ Triton X-100 for $15 \mathrm{~min}$. They were then blocked with 5\% BSA for $1 \mathrm{~h}$. Primary antibody incubations were with the following antibodies: anti-tartrate resistant acid phosphatase (TRAP) (Abcam, ab191406, 1:1,000) in PBS containing $2 \%$ FBS overnight at $4{ }^{\circ} \mathrm{C}$, followed by incubation with goat anti-mouse IgG H\&L (DyLight488) (Abcam, ab96871, 1:400) in PBS containing 2\% FBS as a secondary antibody for $2 \mathrm{~h}$ at room temperature. Finally, the cell nuclei were stained with DAPI $(0.5 \mu \mathrm{g} / \mathrm{mL})$ for $15 \mathrm{~min}$, and images were obtained using a confocal fluorescence microscope. PBS was used for all washing steps. The number of TRAP-positive cells was analyzed by Image J software. At least 3 independent experiments were performed.

\section{Western blot}

Cells were rinsed twice with PBS and lysed in RIPA lysis buffer (Beyotime Institute of Biotechnology), along with PMSF and Phosphatase inhibitor. The lysates were centrifuged, and the supernatants were collected. The protein was separated by $10 \%$ SDS PAGE and transferred to a polyvinylidene difluoride membrane. After blocking with skim milk (5\%) in Tris-buffered saline and Tween20 for $2 \mathrm{~h}$ at room temperature, the membrane was incubated overnight at $4{ }^{\circ} \mathrm{C}$ with the following primary antibodies: anti-PI3K (Abcam, ab151549, 1:1,000), antiP-PI3K (Abcam, ab182651, 1:1,000), Anti-AKT1 (Abcam, ab81283, 1:10,000), Anti-P-AKT1 (Abcam, ab179463, 1:10,000), Anti-JNK1 + JNK2 + JNK3 (Abcam, ab1884195, 1:1,000), Anti-P-JNK1 + JNK2 + JNK3 (Abcam, ab124956, 1:10,000), anti-P38 (Abcam, ab170099, 1:5,000), anti-P-P38 (Abcam, ab4822, 1:1,000), anti-Tartrate Resistant Acid Phosphatase (Abcam, Ab191406, 1:1,000), anti-cathepsin K (Abcam, ab19027, 1:1000), or anti- $\beta$-actin monoclonal antibody (Multi Sciences Biotech, Mab1445, 1:1,000). The membranes were then incubated with secondary antibodies conjugated to horseradish peroxidase (HRP), goat anti-mouse IgG, (GAM0072, Multi Sciences Biotech) or goat anti-rabbit IgG (GAR0072, Multi Sciences Biotech) for $2 \mathrm{~h}$ at room temperature. The membranes were then visualized using an ECL substrate kit (P1425; Multi Sciences Biotech) on the Omega Lum G Imaging System. B-actin levels were used to standardize protein loading. ImageJ software was used to quantify band intensities. At least 3 independent experiments were performed.

\section{Flow cytometric analysis of apoptosis using Annexin V}

The apoptosis of BMMs was analyzed by flow cytometry (Novo Cytec, ACEA, California, USA) using an Annexin V-FITC/PI apoptosis kit (Multi Sciences Biotech, AP101100), according to the manufacturer's protocol. Briefly, cells were washed twice with cold PBS and resuspended in $1 \times$ binding buffer at a density of $1 \times 10^{6}$ cells $/ \mathrm{mL}$; $100 \mu \mathrm{L}$ of the cell suspension was mixed with $5 \mu \mathrm{L}$ FITC Annexin $\mathrm{V}$ and $10 \mu \mathrm{L}$ propidium iodide (PI) and, then gently vortexed and incubated for $15 \mathrm{~min}$ at room temperature $\left(25^{\circ} \mathrm{C}\right)$ in the dark. Then, $400 \mu \mathrm{L}$ of $1 \times$ binding buffer was added to each tube, and apoptosis was analyzed within $1 \mathrm{~h}$. Cell fluorescence was evaluated by flow cytometry (Novo Cytec, ACEA, California, USA; 10,000 cells were analyzed in each sample), and the data were analyzed using Flow Jo 7.6 software. The data showed the percentage of apoptotic cells (Annexin $\mathrm{V}+$ and $\mathrm{PI}+$ ). At least 3 independent experiments were performed. 


\section{Detection of intracellular $\mathrm{Ca}^{2+}$}

The cells were exposed to different concentrations of TAA for $24 \mathrm{~h}$. Then, PBS resuspended cells $\left(1 \times 10^{6}\right.$ cells/ $\mathrm{mL}$ ) were incubated with $400 \mu \mathrm{L} 3 \mu \mathrm{M}$ Fluo-3 AM at $37^{\circ} \mathrm{C}$ for $30 \mathrm{~min}$, with vertical shaking every $5 \mathrm{~min}$. The fluorescent intensity of Fluo-3 AM was measured using flow cytometry (Novo Cytec, ACEA, California, USA; 10,000 cells were analyzed in each sample) with excitation and emission wavelengths at 488 and $540-570 \mathrm{~nm}$, respectively, and the data were analyzed using Flow Jo 7.6 software. The fluorescence intensity was proportional to the concentration of $\mathrm{Ca}^{2+}$. At least 3 independent experiments were performed.

\section{Statistical analysis}

Statistical analysis was performed using Statistical Program for Social Sciences (SPSS) software 19.0. $T$ test was used for statistical analysis among groups. Statistical analysis of all data was performed using GraphPad Prism 7 (GraphPad Software). ${ }^{*} P<0.05,{ }^{* *} P<0.01$ and *:* $P<0.001$ were considered statistically significant. The results from at least three independent experiments were presented as the mean \pm SD.

\section{Results}

Morphology and characterization of BMMs culture in vitro We observed that freshly harvested BMMs were a uniform population; as cells continued to proliferate, the majority of cells became larger, and binuclear or even trinuclear can be seen. After culture for 7 days, the cell morphology changed gradually, the cell volume increased, gradually became irregular, radially adherent disk growth (Fig. 1A).

\section{BMMs proliferation and viability were inhibited by TAA}

We then determined the inhibitory effect of TAA on BMMs using a CCK-8 assay upon exposure of BMMs

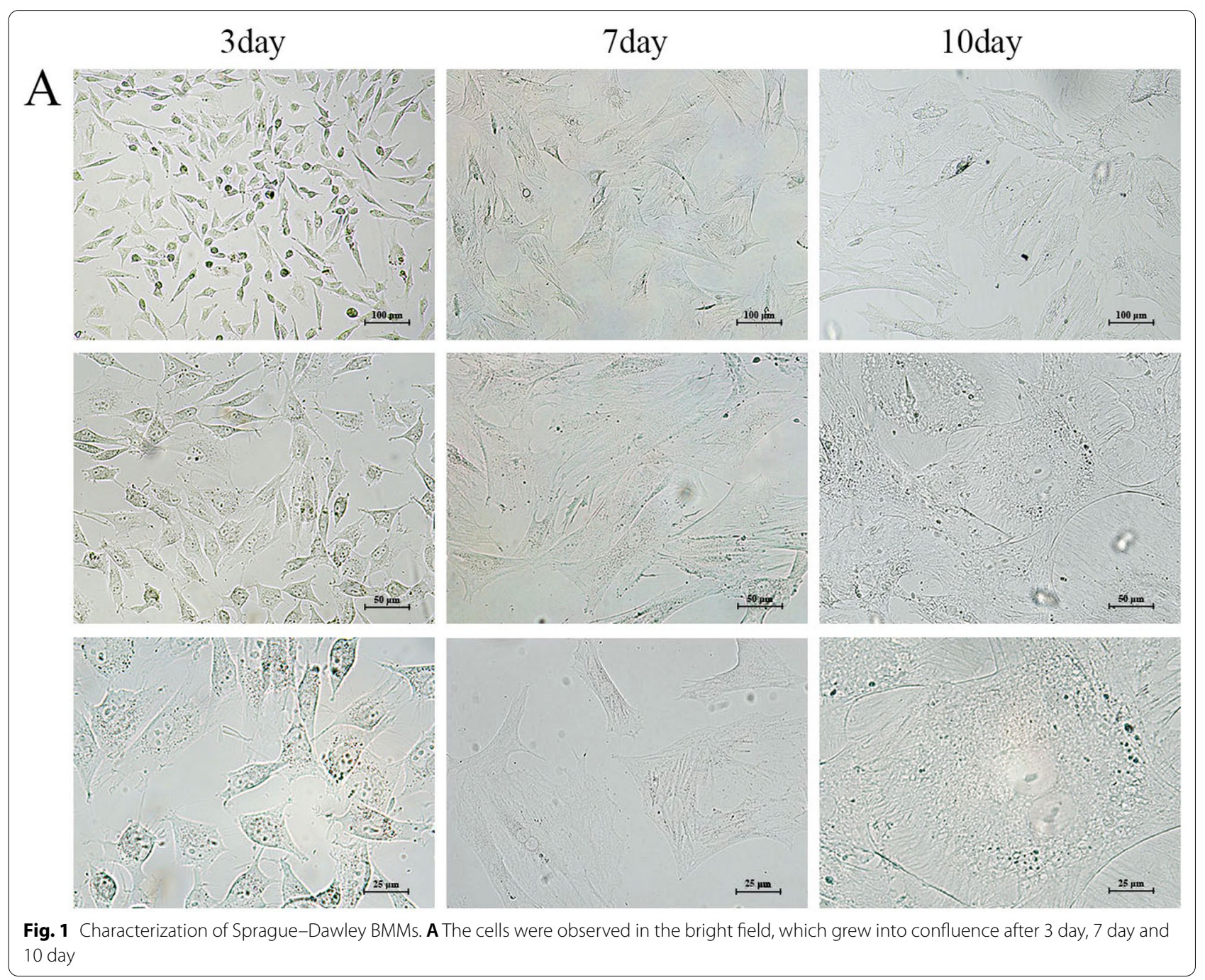


with TAA at concentrations of $0,0.5,1,1.5$ and $2 \mathrm{mg} /$ $\mathrm{mL}$. Cell survival was found to be decreased in a dose and time-dependent manner, and cell viability reached a stable period after $72 \mathrm{~h}$ (Fig. 2B). The results showed that TAA reduced cell viability. Exposed to TAA at a dose of 1.5 and $2 \mathrm{mg} / \mathrm{mL}$ in $24 \mathrm{~h}$, the cell viability was significantly decreased (to approximately 50\%). In all the following experiments, $0.5 \mathrm{mg} / \mathrm{mL}$ and $1 \mathrm{mg} / \mathrm{mL}$ of TAA were selected for further investigation of the effects of TAA on BMMs and exploration of the related mechanisms.

We observed that the division index of $0.5 \mathrm{mg} /$ $\mathrm{mL}$ and $1 \mathrm{mg} / \mathrm{mL}$ TAA-exposed BMMs decreased to $54.1 \% \pm 1.5 \%$ and $51.8 \% \pm 1.9 \%$, respectively, compared to the control $(63.2 \% \pm 3.3 \%)$ after $24 \mathrm{~h}$ in TAA conditions (Fig. $2 \mathrm{C}, \mathrm{D},{ }^{*} P<0.05$ ). The results indicated that TAA could inhibit cell division.

To gain insight into the mechanism of TAA-induced growth inhibition in cells, we analyzed the TAA-dependent changes in the cell cycle distribution (Fig. 2E). Flow cytometric analysis showed that stimulation with TAA for $24 \mathrm{~h}$ caused a substantial increase in the ratio of $S$-phase cells relative to the whole cell population. The percentage of cells in S-phase was significantly increased to $19.4 \% \pm 1.04 \%$ and $25.74 \% \pm 1.77 \%$ in cells exposed to TAA at $0.5 \mathrm{mg} / \mathrm{mL}$ and $1 \mathrm{mg} / \mathrm{mL}$, respectively, compared to $15.98 \% \pm 1.16 \%$ in control cells $\left({ }^{*} P<0.05\right)$. The percentage of cells in G0/G1-phase decreased compared

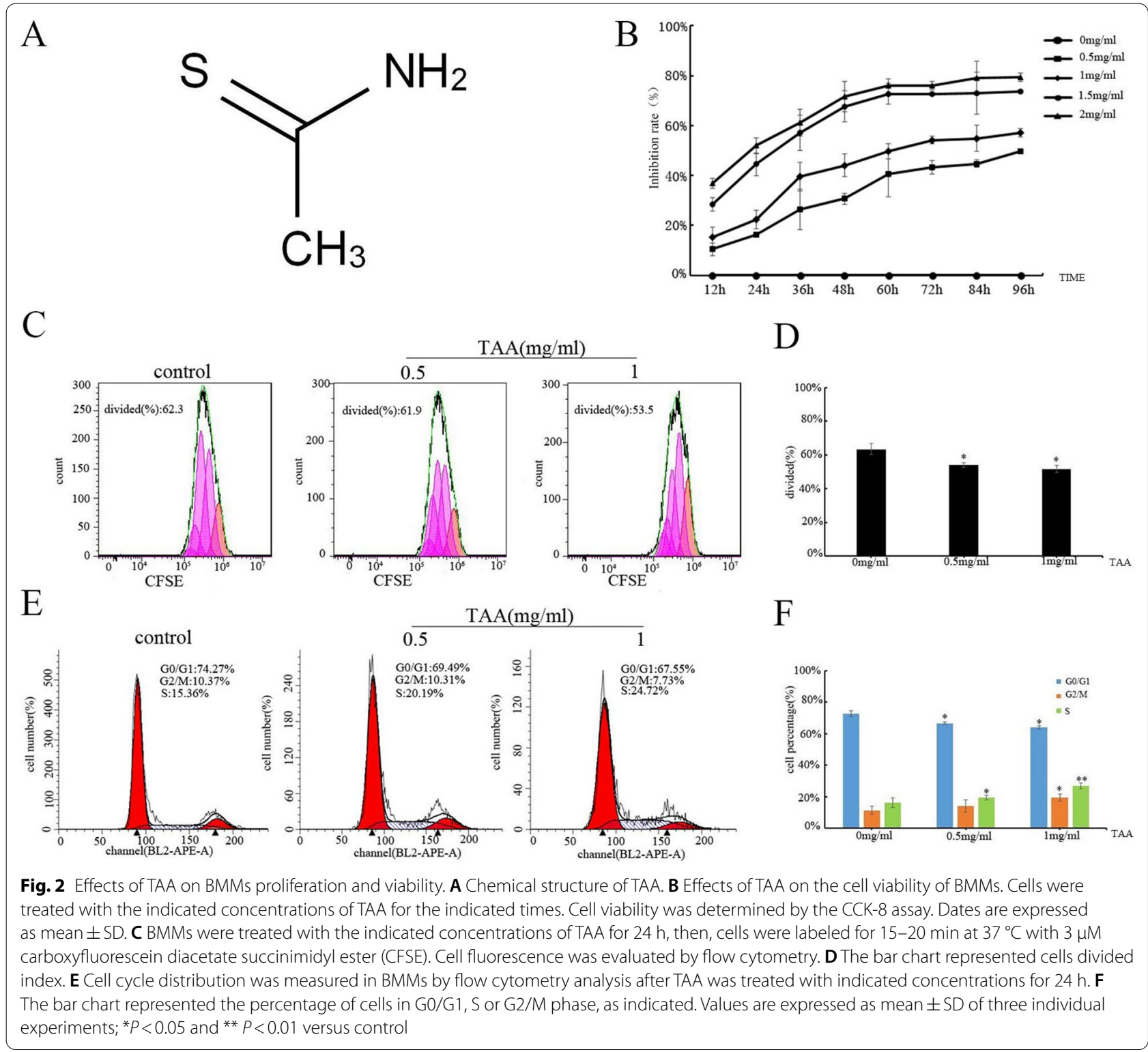


to the control $(67.6 \% \pm 2.54 \%, 64.04 \% \pm 3.05 \%$ vs. $72.78 \% \pm 1.88 \%$, ${ }^{*} P<0.05$, ${ }^{* *} P<0.01$, shown in Fig. $\left.2 \mathrm{~F}\right)$.

\section{Osteoclastic differentiation of BMMs induced by TAA}

To investigate the effects of TAA on the osteoclastogenesis differentiation process of BMMs, immunofluorescence and TRAP staining were used to examine the osteoclast differentiation status of BMMs. We observed cell fusion leading to larger cells, the TRAP staining results of cells exposed to TAA for 7 days showed that the cells were irregular, with three or more nuclei (Fig. 3C). Also, BMMs induced with TAA began to show osteoclast-like morphology. After induced differentiation, TRAP staining results showed that there were few positive purple cells in the control group, while there were a large number of positive purple particles in the cytoplasm of the experimental group. The immunofluorescence results also confirmed this observation (Fig. 3A).

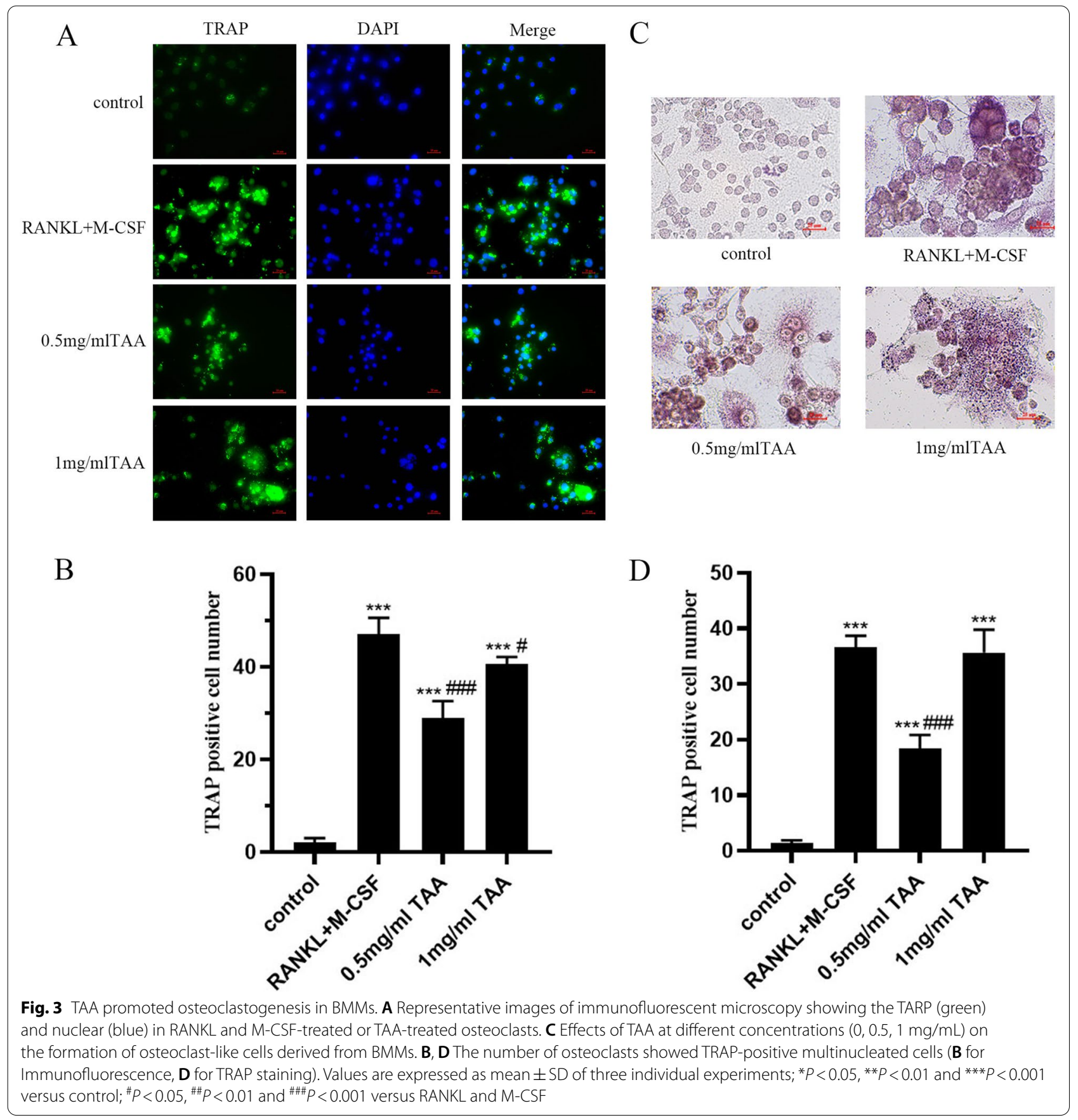


There was almost no TRAP green fluorescence in the control group, while the TRAP fluorescence intensity in RANKL and M-CSF and TAA groups was significantly higher than that in the control group, and the higher the TAA concentration, the stronger the fluorescence intensity. Quantitative analysis showed that the numbers of TRAP-positive cells in the $0.5 \mathrm{mg} / \mathrm{mL}$, and $1 \mathrm{mg} / \mathrm{mL}$ TAA groups were significantly higher than that in the control group $\left({ }^{* * * *} P<0.001\right.$ vs. control Fig. 3$)$.

\section{Effects of TAA on PI3K/AKT pathway and osteoclast-specific protein expression}

To investigate the effect of TAA on PI3K/AKT pathway and osteoclast-specific protein expression in BMMs, we used western blot analysis (Fig. 4). Western blotting showed that TAA exposure activated the protein expression of P-PI3K, P-AKT, P-P38, P-JNK, and promoted the expression of osteoclast-specific protein TRAP and cathepsin K. These results demonstrate that TAA exposure may promote osteoclast transformation of bone marrow cells by activating PI3K/AKT pathway-related proteins.
TAA exposure increases intracellular $\mathrm{Ca}^{2+}$ and promotes apoptosis

Next, we explored whether TAA induced BMMs apoptosis. Figure 5A, B shows that, as the concentration of TAA increased, the percentage of apoptotic BMMs increased. To further explore whether TAA was a calcium channel blocker, intracellular $\mathrm{Ca}^{2+}$ was detected by evaluating the fluorescent intensity of Fluo-3 AM. As shown in Fig. 5C, $\mathrm{D}$, as the TAA concentration increased from 0 to $0.5 \mathrm{mg} /$ $\mathrm{mL}$ and $1 \mathrm{mg} / \mathrm{mL}$, the fluorescent intensity of Fluo-3 AM increased from 4.16 to $12.2 \%$ and $27.81 \%$, respectively. The results indicated that BMMs intracellular $\mathrm{Ca}^{2+}$ were increased upon exposed to TAA.

\section{Discussion}

Overactivation of bone resorption plays a critical role in the pathological mechanisms of osteoporosis [34]. Osteoclasts, as the unique multinucleated cells that can dissolve bone matrix, are derived from the monocyte/ macrophage lineage of hematopoietic precursors [35]. It has been confirmed that these progenitor cells fuse to form osteoclasts under the effect of RANKL and M-CSF.

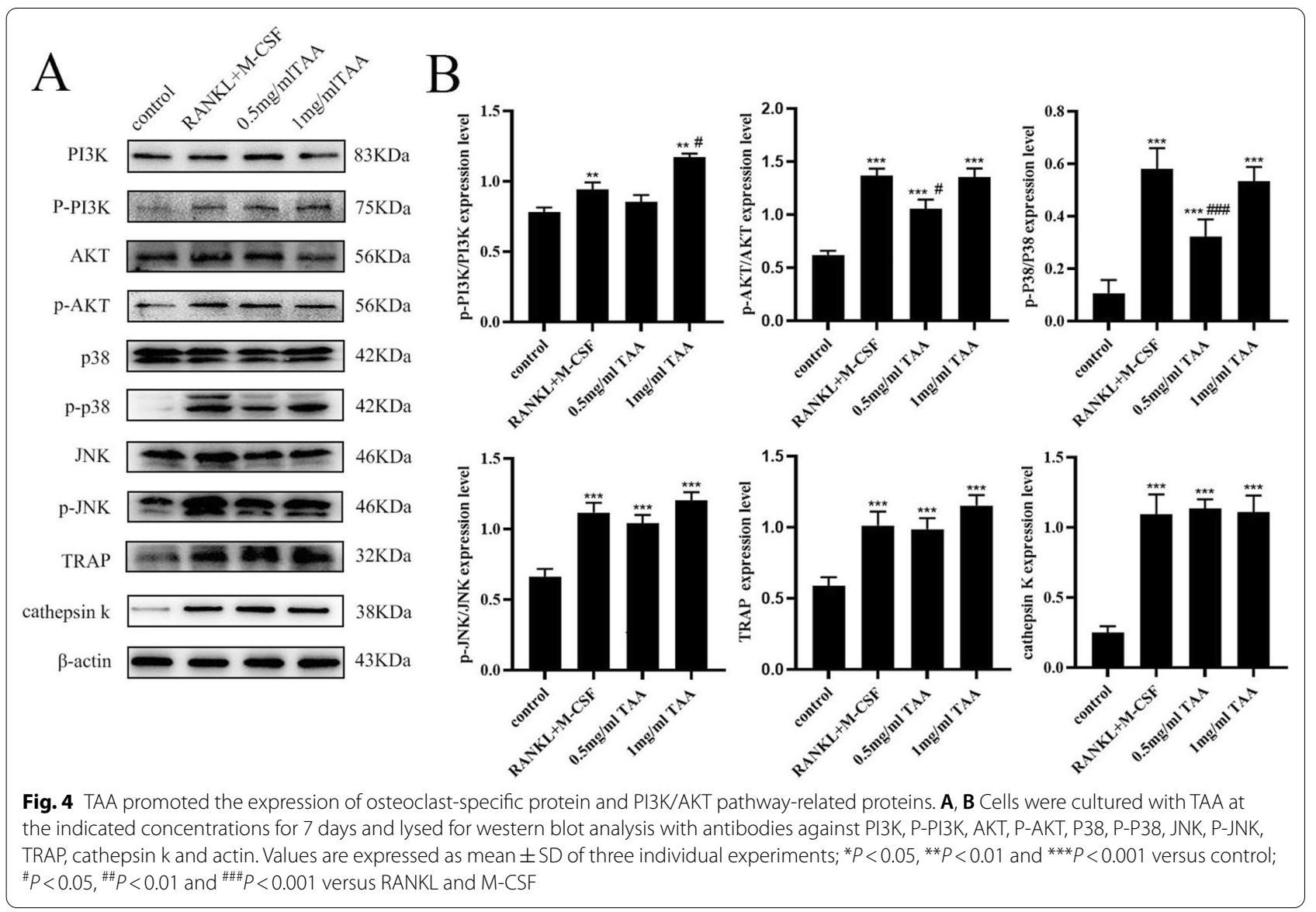



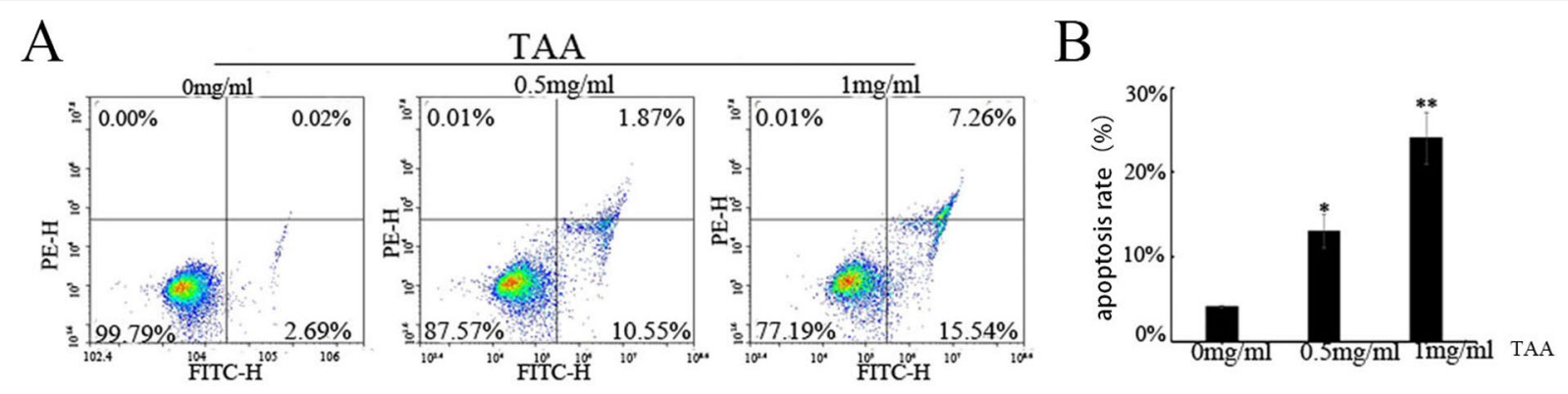

C

TAA
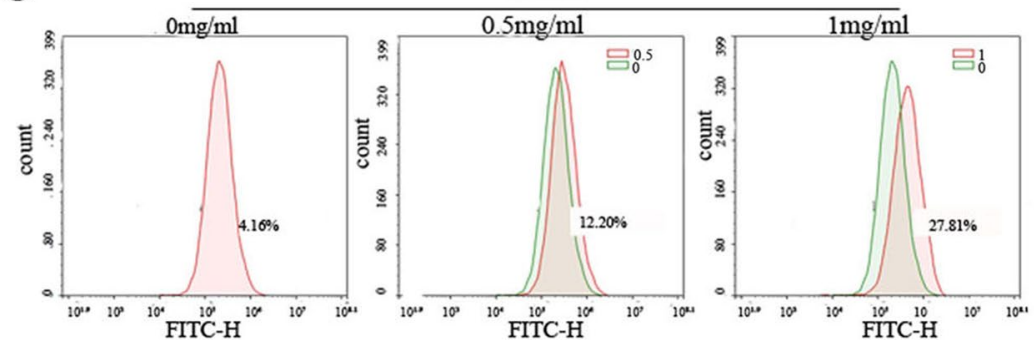

D

Fig. 5 TAA exposure increases intracellular $\mathrm{Ca}^{2+}$ and promotes apoptosis. A Quantification of cell apoptosis by flow cytometry. BMMs were treated with TAA at the indicated concentrations for $24 \mathrm{~h}$, then, cells were incubated with FITC Annexin V in a buffer containing propidium iodide (PI) and analyzed by FCM. B Statistical bar graph showing the apoptosis ratio. C Analysis of intracellular $\mathrm{Ca}^{2+}$ in BMMs. Cells were treated with TAA at the indicated concentrations, then the cells were incubated with $400 \mu \mathrm{L} 5 \mu \mathrm{M}$ Fluo-3 AM at $37^{\circ} \mathrm{C}$ for $30 \mathrm{~min}$. The fluorescent intensity of Fluo-3 AM was measured by the flow cytometry analysis at $488 \mathrm{~nm}$ (excitation) and 540-570 $\mathrm{nm}$ (emission). D The bar chart represented the intensity of fluo-3 AM in cells. Values are expressed as mean \pm SD of three individual experiments; ${ }^{*} P<0.05,{ }^{* *} P<0.01$ and ${ }^{* *} P<0.001$ versus control

Previous studies have found that propranolol can promote osteoclastogenesis of mesenchymal stem cells (MScs) while inhibiting their proliferation, explaining that cell proliferation and differentiation can influence each other [36]. TAA is a potent experimental hepatotoxin and hepato-carcinogenic compound that is often used to induce fulminant hepatic failure in experimental animal models [37]. Our research shows that TAA has a toxic effect on BMMs, and can inhibit the proliferation of BMMs in a dose- and time-dependent manner in vitro. TAA can even promote the apoptosis of BMMs, which may be caused by the increase in intracellular calcium. More importantly, we show for the first time that TAA may be directly related to osteoclastogenesis and can induce BMMs to differentiate into osteoclast-like cells. 0.5 or $1 \mathrm{mg} / \mathrm{mL}$ TAA has less toxic effects on BMMs, because its main effect on BMMs may be to induce osteoclast differentiation, inhibit cell proliferation during the differentiation process, and promote cell apoptosis.

P2X7/PI3K/AKT pathway has been shown to regulate osteoclast survival and differentiation. Ma [38] found that the suppression of PI3K/AKT signaling was further inhibited osteoclast and osteoblast differentiation after long-term $\mathrm{Cd}$ exposure. Under the stimulation of RANKL and M-CSF, PI3K/AKT pathway proteins are activated in osteoclast precursor cells and modulate osteoclastogenesis and osteoclast activity [39-42]. 0.5 or $1 \mathrm{mg} / \mathrm{mL}$ TAA can promote osteoclast differentiation, and the effect is similar to RANKL and M-CSF. Same as the previous reports, our results showed that TAA promoted the expression of $\mathrm{p}-\mathrm{PI} 3 \mathrm{~K}, \mathrm{p}-\mathrm{AKT}, \mathrm{p}-\mathrm{P} 38$ and $\mathrm{p}$-JNK, indicating that it may promote osteoclast differentiation by activating the PI3K/AKT pathway (Fig. 4).

In conclusion, our data show that TAA affects the proliferation of BMMs, arrests them in S-phase and promotes their apoptosis. But the most important finding is that 0.5 or $1 \mathrm{mg} / \mathrm{mL}$ TAA may promote the osteoclast transformation of BMMs by activating the PI3K/AKT pathway, and promoting the expression of osteoclast-specific proteins TRAP and Cathepsin $\mathrm{K}$, which is equivalent to RANKL and M-CSF. So, we hypothesize that TAA may have a similar effect to RANKL and M-CSF, which can induce the formation of osteoclasts. RANKL and M-CSF are expensive and not readily available, while TAA may be an inexpensive alternative. The potential of TAA to induce osteoclasts suggests that we may have found a cheap osteoclast inducer. In order to further prove the effect of TAA on osteoclast differentiation, current efforts are directed at evaluating the effects of TAA on osteoclast differentiation in vivo. 


\section{Abbreviations}

TAA: Thioacetamide; BMMs: Bone marrow macrophages; M-CSF: Macrophage colony-stimulating factor; RANKL: Receptor activator of nuclear factor kappa $B$ ligand.

\section{Acknowledgements}

This work was supported by the Natural Science Foundation of Zhejiang Province (No. LY19H060001), Zhejiang Province Project of the Science Technology Department (No. 2015C37113), Zhejiang Traditional Chinese Medicine Science and Technology Plan Project (No. 2022ZB093).

\section{Authors' contributions}

$X L J, Y L, J C$ and $Y Y Y$ participated in the planning and design of the experiments. $X L J$ and $Y L$ performed the experiments and wrote the manuscript. $X L J$, YYY performed the experiments. JX and BX designed and discussed the study data, supervised the entire project, and edited the final manuscript. All authors read and approved the final manuscript.

\section{Availability of data and materials}

The data that support the findings of this study are available from the corresponding author upon reasonable request.

\section{Declarations}

\section{Ethics approval and consent to participate}

All animal experiments were approved by the Animal Ethical and Welfare Committee of ZCMU (Approval No. IACUC-20191223-07).

\section{Consent for publication}

Not applicable.

\section{Competing interests}

The authors declare no competing interests.

\section{Author details}

${ }^{1}$ School of Medical Technology and Information Engineering, Zhejiang Chinese Medical University, Hangzhou 310053, China. ${ }^{2}$ School of Basic Medical Sciences, FUDAN University, Shanghai 200433, People's Republic of China. ${ }^{3}$ Department of Laboratory Medicine, The First People's Hospital of Shangqiu, Shangqiu 476000, China. ${ }^{4}$ Department of General Surgery, School of Medicine, Sir Run Run Shaw Hospital, Zhejiang University, Hangzhou 310016, Zhejiang, People's Republic of China.

Received: 23 September 2021 Accepted: 12 January 2022 Published online: 29 January 2022

\section{References}

1. Tsukamoto H. Development of new palladium (0)-catalyzed reactions based on novel oxidative addition mode. Yakugaku Zasshi. 2008;128(9):1259-66.

2. Durmusoglu EG, Selopal GS, Mohammadnezhad M, Zhang H, Dagtepe $\mathrm{P}$, Barba D, et al. Low-cost, air-processed quantum dot solar cells via diffusion-controlled synthesis. ACS Appl Mater Interfaces. 2020;12(32):36301-10.

3. Jin Z, Liu Y, Hao X. Self-assembly of zinc cadmium sulfide nanorods into nanoflowers with enhanced photocatalytic hydrogen production activity. J Colloid Interface Sci. 2020:567:357-68.

4. Hedlund JK, Estrada TG, Walker AV. Chemical bath deposition of copper sulfide on functionalized SAMs: an unusual selectivity mechanism. Langmuir. 2020;36(12):3119-26.

5. Constantinou MA, Theocharis SE, Mikros E. Application of metabonomics on an experimental model of fibrosis and cirrhosis induced by thioacetamide in rats. Toxicol Appl Pharmacol. 2007;218(1):11-9.

6. Boyer-Diaz Z, Aristu-Zabalza P, Andrés-Rozas M, Robert C, Ortega-Ribera M, Fernández-Iglesias A, et al. Pan-PPAR agonist lanifibranor improves portal hypertension and hepatic fibrosis in experimental advanced chronic liver disease. J Hepatol. 2020;8278(20):33832-40.

7. Marciniak S, Wnorowski A, Smolińska K, Walczyna B, Turski W, Kocki T, et al. Kynurenic acid protects against thioacetamide-induced liver injury in rats. Anal Cell Pathol (Amsterdam). 2018;28(9):1-11.

8. Zargar S, Alonazi M, Rizwana H, Wani TA. Resveratrol reverses thioacetamide-induced renal assault with respect to oxidative stress, renal function, DNA damage, and cytokine release in wistar rats. Oxid Med Cell Longev. 2019;27(2):1-8.

9. Caballero ME, Berlanga J, Ramirez D, Lopez-Saura P, Gozalez R, Floyd DN, et al. Epidermal growth factor reduces multiorgan failure induced by thioacetamide. Gut. 2001;48(1):34-40.

10. Avraham Y, Grigoriadis NC, Magen I, Poutahidis T, Vorobiav L, Zolotarev $\mathrm{O}$, et al. Capsaicin affects brain function in a model of hepatic encephalopathy associated with fulminant hepatic failure in mice. $\mathrm{Br} J \mathrm{Pharmacol}$. 2009:158(3):896-906.

11. Latha SM, Pai MR, Pai PK. Thioacetamide toxicity and the lung: histological analysis. Indian J Physiol Pharmacol. 2003;47(4):476-8.

12. Kadir FA, Kassim NM, Abdulla MA, Yehye WA. Effect of oral administration of ethanolic extract of Vitex negundo on thioacetamide-induced nephrotoxicity in rats. BMC Complement Altern Med. 2013;13(1):294-301.

13. Gao W, Li HY, Wang LX, Hao LJ, Gao JL, Zheng RJ, et al. Protective effect of omeprazole on gastric mucosal of cirrhotic portal hypertension rats. Asian Pac J Trop Med. 2014;7(5):402-6.

14. Lin D, Wu X, Ji X, Zhang Q, Lin Y, Chen W, et al. A novel canine model of portal vein stenosis plus thioacetamide administration-induced cirrhotic portal hypertension with hypersplenism. Cell Biochem Biophys. 2012;62(1):245-55.

15. El-Marasy SA, El Awdan SA, Abd-Elsalam RM. Protective role of chrysin on thioacetamide-induced hepatic encephalopathy in rats. Chem Biol Interact. 2019:299(1):111-9.

16. Lassila $V$, Virtanen P. Influence of experimental liver injury on rat blood and alveolar bone under stress. Acta Anat (Basel). 1984:118(2):116-21.

17. Virtanen $P$, Lassila V. Influence of thioacetamide-provoked liver injury on female rat blood and alveolar bone under stress. Acta Anat (Basel). 1986:127(4):285-9.

18. Nakano A, Kanda T, Abe H. Bone changes and mineral metabolism disorders in rats with experimental liver cirrhosis. J Gastroenterol Hepatol. 1996;11(12):1143-54

19. Batoon L, Millard SM, Raggatt LJ, Pettit AR. Osteomacs and bone regeneration. Curr Osteoporos Rep. 2017;15(4):385-95.

20. Meng B, Wu D, Cheng Y, Huang P, Liu Y, Gan L, et al. Interleukin-20 differentially regulates bone mesenchymal stem cell activities in RANKL-induced osteoclastogenesis through the OPG/RANKL/RANK axis and the NF-KB, MAPK and AKT signalling pathways. Scand J Immunol. 2020;91(5):12874-86

21. Ramchand SK, Seeman E. The influence of cortical porosity on the strength of bone during growth and advancing age. Curr Osteoporos Rep. 2018;16(5):561-72.

22. Rodan GA, Martin TJ. Therapeutic approaches to bone diseases. Science. 2000:289(5484):1508-14

23. Zeng X, Zhang Y, Wang S, Wang K, Tao L, Zou M, et al. Artesunate suppresses RANKL-induced osteoclastogenesis through inhibition of PLCY1-

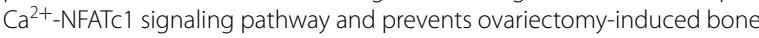
oss. Biochem Pharmacol. 2017:124:57-68.

24. Walsh MC, Takegahara N, Kim H, Choi Y. Updating osteoimmunology: regulation of bone cells by innate and adaptive immunity. Nat Rev Rheumatol. 2018;14(3):146-56.

25. Coury F, Peyruchaud O, Machuca-Gayet I. Osteoimmunology of bone loss in inflammatory rheumatic diseases. Front Immunol. 2019;10:679-88.

26. Choo YY, Tran PT, Min BS, Kim O, Nguyen HD, Kwon SH, et al. Sappanone A inhibits RANKL-induced osteoclastogenesis in BMMs and prevents inflammation-mediated bone loss. Int Immunopharmacol. 2017:52:230-7.

27. Bunte $\mathrm{K}$, Beikler T. Th17 cells and the $\mathrm{IL}-23 / \mathrm{LL}-17$ axis in the pathogenesis of periodontitis and immune-mediated inflammatory diseases. Int J Mol Sci. 2019;20(14):3394-418.

28. Takeshita S, Kaji K, Kudo A. Identification and characterization of the new osteoclast progenitor with macrophage phenotypes being able to differentiate into mature osteoclasts. J Bone Miner Res. 2000;15(8):1477-88. 
29. Udagawa N, Koide M, Nakamura M, Nakamichi Y, Yamashita T, Uehara S, et al. Osteoclast differentiation by RANKL and OPG signaling pathways. J Bone Miner Metab. 2021;39(1):19-26.

30. Koga T, Inui M, Inoue K, Kim S, Suematsu A, Kobayashi E, et al. Costimulatory signals mediated by the ITAM motif cooperate with RANKL for bone homeostasis. Nature. 2004;428(6984):758-63.

31. Boyle WJ, Simonet WS, Lacey DL. Osteoclast differentiation and activation. Nature. 2003:423(6937):337-42.

32. Park H, Noh AL, Kang JH, Sim JS, Lee DS, Yim M. Peroxiredoxin II negatively regulates lipopolysaccharide-induced osteoclast formation and bone loss via JNK and STAT3. Antioxid Redox Signal. 2015;22(1):63-77.

33. Lu J, Ye C, Huang Y, Huang D, Tang L, Hou W, et al. Corilagin suppresses RANKL-induced osteoclastogenesis and inhibits oestrogen deficiencyinduced bone loss via the NF-KB and PI3K/AKT signalling pathways. J Cell Mol Med. 2020;24(18):10444-57.

34. Stucker S, Chen J, Watt FE, Kusumbe AP. Bone angiogenesis and vascular niche remodeling in stress, aging, and diseases. Front Cell Dev Biol. 2020;8:602269-89.

35. Xiong Q, Zhang L, Zhan S, Ge W, Tang P. Investigation of proteome changes in osteoclastogenesis in low serum culture system using quantitative proteomics. Proteome Sci. 2016;14(8):1-13.

36. Wu Y, Zhang Q, Zhao B, Wang X. Effect and mechanism of propranolol on promoting osteogenic differentiation and early implant osseointegration. Int J Mol Med. 2021:48(4):191-203.

37. Sarkar MK, Sil PC. Hepatocytes are protected by herb Phyllanthus niruri protein isolate against thioacetamide toxicity. Pathophysiology. 2007;14(2):113-20.

38. Ma Y, Ran D, Cao Y, Zhao H, Song R, Zou H, et al. The effect of P2X7 on cadmium-induced osteoporosis in mice. J Hazard Mater. 2021;405(26):124251-63.

39. Leibbrandt A, Penninger JM. RANK/RANKL: regulators of immune responses and bone physiology. Ann N Y Acad Sci. 2008;1 143:123-50.

40. Jin H, Wang Q, Chen K, Xu K, Pan H, Chu F, et al. Astillbin prevents bone loss in ovariectomized mice through the inhibition of RANKL-induced osteoclastogenesis. J Cell Mol Med. 2019;23(12):8355-68.

41. Mandal CC, Ghosh Choudhury G, Ghosh-Choudhury N. Phosphatidylinositol 3 kinase/Akt signal relay cooperates with smad in bone morphogenetic protein-2-induced colony stimulating factor-1 (CSF-1) expression and osteoclast differentiation. Endocrinology. 2009;150(11):4989-98.

42. Zhao Y, Xu Y, Zheng H, Lin N. Qing Yan Formula extracts protect against postmenopausal osteoporosis in ovariectomized rat model via active ERdependent MEK/ERK and PI3K/Akt signal pathways. J Ethnopharmacol. 2020;29:113644-56

\section{Publisher's Note}

Springer Nature remains neutral with regard to jurisdictional claims in published maps and institutional affiliations.

Ready to submit your research? Choose BMC and benefit from:

- fast, convenient online submission

- thorough peer review by experienced researchers in your field

- rapid publication on acceptance

- support for research data, including large and complex data types

- gold Open Access which fosters wider collaboration and increased citations

- maximum visibility for your research: over $100 \mathrm{M}$ website views per year

At BMC, research is always in progress.

Learn more biomedcentral.com/submissions 